\title{
S-gene polymorphism in Phlox drummondii
}

\author{
DONALD A. LEVIN \\ Department of Botany, University of Texas, Austin, TX 78731, U.S.A.
}

\begin{abstract}
The genetic control of self-incompatibility and the number of $S$-alleles were studied in a population of Phlox drummondii from Lytle, Texas. Thirty-four seedlings were transplanted to the greenhouse. Each was self-fertilized (using bud pollination) to generate self families of 9-11 plants. Complete diallels were performed within each family. Twenty-four families contained three crosscompatibility phenotypes whose crossing relationships indicated that self-incompatibility was under gametophytic control and governed by one gene. Homozygotes from twenty-four families were crossed in a half-diallel for $S$-genotype assignment. Thirty $S$-alleles were detected. Allele frequencies did not deviate significantly from equality.
\end{abstract}

Keywords: allelic diversity, breeding systems, pseudo-compatibility, self-incompatibility.

\section{Introduction}

Experimental investigation of the self-incompatibility ( $S$-gene) polymorphism has at the outset a conceptual framework generally unavailable for other polymorphisms (Wright, 1939, 1964; Fisher, 1958; Ewens, 1964; Crosby, 1966; Nagylaki, 1975; Yokoyama \& Nei, 1979; Yokoyama \& Hetherington, 1982). The selective advantage of an allele is negatively related to its frequency in the population, and the number of different alleles in a population is potentially very large. Population subdivision by virtue of restricted gene flow will increase the number of alleles that can be retained within a population. The frequencies of each of $k$ alleles are expected to be approximately $1 / k$, provided that the population is in equilibrium and that the effect of selection on the gene is limited to that associated with incompatibility.

In spite of this conceptual framework, $S$-gene polymorphism in natural populations is not well understood. It has been described in only four species with gametophytic self-incompatibility (Oenothera organensis, Emerson, 1939, 1940; Trifolium repens, Atwood, 1944; Trifolium pratense, Williams \& Williams, 1947; Papaver rhoeas, Campbell \& Lawrence, 1981a,b; Lawrence \& O'Donnell, 1981), and in only four species with sporophytic self-incompatibility (Iberis amara, Bateman, 1954; Raphanus raphanistrum, Sampson, 1967; Raphanus sativus, Karron et al., 1990; Sinapis arvensis, Ford \& Kay, 1985; Stevens \& Kay, 1989).

The purpose of this study was to establish the genetics of self-incompatibility in Phlox drummondii
Hook., and to identify $S$-allele genotypes and gene frequencies in one population. This species has a strong, but surmountable, incompatibility system (Levin, 1985). Crosses between plants of different degrees of relatedness suggested that self-incompatibility was under gametophytic control (Levin, 1989). Pollen is binucleate, and the incompatibility reaction occurs on the surface of the stigma (Levin, 1975). This species is almost exclusively outcrossing in natural populations (Watkins \& Levin, 1990). Deviations from panmixia ostensibly are the result of breeding between relatives.

\section{Materials and methods}

In January 1989, 34 plants were transplanted as seedlings from a population in Lytle, Atascosa Co., Texas. The transplants were from a $50 \mathrm{~m} \times 50 \mathrm{~m}$ area in the centre of the population. To reduce the chance of sampling full- or half-sibs, the plants chosen for transplanting were at least $5 \mathrm{~m}$ apart. This population was chosen for study because earlier investigations showed plants therein to be strongly self-incompatible. Some $P$. drummondii populations are weakly self-compatible (Levin, 1985). As will be discussed below, this condition obfuscates the breeding programme used in this study.

Each transplant was self-fertilized, using bud pollination to circumvent the incompatibility barrier. The 34 families obtained by this method each contained 9-11 plants, referred to as self-sibs.

Plants within each family were crossed in a complete diallel to identify the $S$-allele homozygotes and heterozygotes. Four pollinations were made per crossing 
combination. Plants were considered cross-compatible if any of the pollinations bore fruit.

If incompatibility was governed by one gene, the transplants would be heterozygous and each family would contain three cross-compatibility phenotypes, corresponding to three genotypes $\left(S_{\mathrm{x}} S_{\mathrm{x}}, S_{\mathrm{x}} S_{\mathrm{y}}, S_{\mathrm{y}} S_{\mathrm{y}}\right)$, in a 1:2:1 ratio as shown in Table 1 .

If incompatibility was under gametophytic control, four of the nine possible crossing combinations between three phenotypes (using each as a male and female parent) would be fruitful (Table 1). Reciprocal crosses between homozygotes and heterozygotes would be successful in only one direction. If incompatibility were under sporophytic control, only two of the nine possible crossing combinations would be successful (Table 1). Reciprocal crosses would be successful in both directions or not at all. If one $S$-allele were dominant over another, there would be two crosscompatibility phenotypes.

Plants which failed to set seed when pollen from other family members was placed on their stigmas were judged to be heterozygotes (Table 1). Plants which set seed were judged to be homozygotes. Homozygotes which successfully interbred were considered to have different genotypes (i.e. $S_{x} S_{x}$ and $S_{y} S_{y}$ ). Homozygotes which failed to interbreed were considered to have the same genotype.

One plant of each of the two homozygotes per family was self-fertilized (using bud pollination) to generate the $S$-gene homozygotes used in the genotype assignment programme. The homozygotes from each of the 30 families were intercrossed in a half-diallel. Initially two pollinations were made per crossing combination. If no fruits were obtained, two more pollinations were made. If no fruits were obtained then, the homozygotes were assumed to have the same genotype. If fruits were obtained, the homozygotes were assumed to have different genotypes.

Table 1 Expected crossing relationships among three crosscompatibility phenotypes with gametophytic determination of pollen specificity

Pollen parent

\begin{tabular}{lllll}
\cline { 3 - 4 } Egg parent & I & II & III \\
\hline I & $\left(S_{x} S_{x}\right)$ & - & $+(-)^{*}$ & + \\
II & $\left(S_{y} S_{y}\right)$ & - & - & - \\
III & $\left(S_{y} S_{y}\right)$ & + & $+(-)^{*}$ & - \\
\hline
\end{tabular}

*Crosses would be incompatible if pollen specificity were determined sporophytically.

+Denotes compatible crosses, - denotes incompatible crosses.
The two homozygotes from the first family were designated $S_{1} S_{1}$ and $S_{2} S_{2}$, respectively; and the genotype of the transplant from which the family was derived thus was $S_{1} S_{2}$. If both homozygotes from the second family crossed successfully with both homozygotes from the first family, their genotypes would be $S_{3} S_{3}$ and $S_{4} S_{4}$, respectively, and the second transplant's genotype would be $S_{3} S_{4}$. If one of the homozygotes in the second family failed to cross with homozygote $S_{1} S_{1}$, the allele was assumed to be shared, and the genotype of the transplant would be $S_{1} S_{3}$. The rest of the plants were assigned genotypes on the basis of their crossing relationships with the plants whose genotypes had been designated.

In plants, such as Phlox, where pollen segregates for incompatibility phenotype, scoring the percentage pollen on stigmas sending tubes into the pistil would indicate whether plants share one allele, both alleles or neither. This procedure was not employed because of the time necessary to stain and score pollen grains and pollen tubes, the large number of crosses being performed, and the need to identify and self-fertilize homozygous plants as soon as possible.

The use of seed-set to determine whether plants share $S$-alleles is less desirable than observations of pollen behaviour on stigmas because failure to set seed might not result from pollen-pistil incompatibility. In this study, the overall probability of fruit-set failure for a compatible cross is 0.3 , and thus the probability of four compatible crosses setting no seed is $(0.3)^{4}=0.81$ per cent. Thus it is possible that one or perhaps two crossing combinations classified as incompatible were misclassified.

\section{Results}

Three cross-compatibility phenotypes were demonstrated in 24 of the 34 intrafamily diallels. The crossing behaviour of these phenotypes conforms to that expected with gametophytic self-incompatibility as described above. The outcome of crosses within family 3 illustrates this point (Table 2).

The numbers of plants per cross-compatibility phenotype are shown for the 24 families in Table 3 . The most frequent homozygous phenotype is designated I. Homozygotes exceeded heterozygotes in 11 families. Heterozygotes exceeded homozygotes in seven families and were equal to them in six families.

Four families $(12,30,33,34)$ contained only two cross-compatibility phenotypes, as illustrated in Table 4. The plants in these groups showed unilateral incompatibility when intercrossed, indicating that one group was homozygous and the other was heterozygous. Presumably the second homozygote was not recovered because of small sample size. 
Table 2 Percentage fruit-set from a diallel in family 3

\begin{tabular}{|c|c|c|c|c|c|c|c|c|c|c|c|}
\hline \multirow{3}{*}{\multicolumn{2}{|c|}{ Egg parent }} & \multicolumn{10}{|c|}{ Pollen parent } \\
\hline & & \multicolumn{3}{|l|}{ I } & \multicolumn{4}{|l|}{ II } & \multicolumn{3}{|l|}{ III } \\
\hline & & 1 & 3 & 10 & 2 & 5 & 8 & 9 & 4 & 6 & 7 \\
\hline \multirow[t]{3}{*}{ I } & 1 & & 0 & 0 & 50 & 75 & 75 & 100 & 100 & 50 & 25 \\
\hline & 3 & 0 & & 0 & 75 & 50 & 100 & 75 & 25 & 100 & 75 \\
\hline & 10 & 0 & 0 & & 100 & 25 & 50 & 50 & 50 & 75 & 75 \\
\hline \multirow[t]{4}{*}{ II } & 2 & 0 & 0 & 0 & & 0 & 0 & 0 & 0 & 0 & 0 \\
\hline & 5 & 0 & 0 & 0 & 0 & & 0 & 0 & 0 & 0 & 0 \\
\hline & 8 & 0 & 0 & 0 & 0 & 0 & & 0 & 0 & 0 & 0 \\
\hline & 9 & 0 & 0 & 0 & 0 & 0 & 0 & & 0 & 0 & 0 \\
\hline \multirow[t]{3}{*}{ III } & 4 & 100 & 25 & 75 & 75 & 100 & 50 & 50 & & 0 & 0 \\
\hline & 6 & 75 & 100 & 100 & 25 & 50 & 75 & 75 & 0 & & 0 \\
\hline & 7 & 50 & 100 & 75 & 75 & 100 & 75 & 100 & 0 & 0 & \\
\hline
\end{tabular}

Roman numerals refer to the cross-compatibility phenotype; arabic numerals refer to individual plants.

Table 3 Distribution of plants in crossing phenotypes within families

\begin{tabular}{llll}
\hline & \multicolumn{2}{l}{ Crossing phenotype } \\
\cline { 2 - 4 } Family & I & II & III \\
\hline 1 & 4 & 5 & 1 \\
2 & 4 & 2 & 3 \\
4 & 5 & 3 & 2 \\
5 & 2 & 4 & 2 \\
7 & 3 & 5 & 3 \\
9 & 4 & 4 & 2 \\
10 & 3 & 7 & 1 \\
11 & 4 & 5 & 1 \\
13 & 3 & 6 & 2 \\
14 & 3 & 5 & 2 \\
15 & 4 & 4 & 2 \\
17 & 2 & 6 & 2 \\
18 & 4 & 4 & 1 \\
19 & 2 & 7 & 1 \\
20 & 3 & 5 & 2 \\
21 & 2 & 6 & 1 \\
22 & 3 & 6 & 2 \\
23 & 5 & 3 & 1 \\
24 & 3 & 4 & 2 \\
26 & 3 & 5 & 2 \\
27 & 6 & 2 & 1 \\
28 & 5 & 3 & 1 \\
31 & 5 & 2 & \\
32 & 2 & 5 & \\
\hline
\end{tabular}

Table 4 Percentage fruit-set in a diallel in family 30

\begin{tabular}{|c|c|c|c|c|c|c|c|c|c|c|}
\hline \multirow{3}{*}{\multicolumn{2}{|c|}{$\begin{array}{l}\text { Egg } \\
\text { parent }\end{array}$}} & \multicolumn{9}{|c|}{ Pollen parent } \\
\hline & & \multicolumn{4}{|l|}{ I } & \multicolumn{5}{|l|}{ II } \\
\hline & & 2 & 5 & 6 & 9 & 1 & 3 & 4 & 7 & 8 \\
\hline \multirow[t]{4}{*}{ I } & 2 & & 0 & 0 & 0 & 50 & 75 & 50 & 100 & 25 \\
\hline & 5 & 0 & & 0 & 0 & 25 & 50 & 75 & 25 & 100 \\
\hline & 6 & 0 & 0 & & 0 & 50 & 75 & 75 & 75 & 100 \\
\hline & 9 & 0 & 0 & 0 & & 75 & 100 & 100 & 25 & 100 \\
\hline \multirow[t]{5}{*}{ II } & 1 & 0 & 0 & 0 & 0 & & 0 & 0 & 0 & 0 \\
\hline & 3 & 0 & 0 & 0 & 0 & 0 & & 0 & 0 & 0 \\
\hline & 4 & 0 & 0 & 0 & 0 & 0 & 0 & & 0 & 0 \\
\hline & 7 & 0 & 0 & 0 & 0 & 0 & 0 & 0 & & 0 \\
\hline & 8 & 0 & 0 & 0 & 0 & 0 & 0 & 0 & & 0 \\
\hline
\end{tabular}

Roman numerals refer to crossing phenotypes; arabic numerals refer to individual plants.

Phenotypic classes could not be distinguished in six families. In families 3,8 and 2, nearly every cross was incompatible in both directions. However, plants which failed to cross successfully as a pollen or egg parent within its familiy crossed successfully with plants from other families. For example, plant 2 from family 25 was an effective pollen and egg parent with 16 of 24 unrelated plants with which it was crossed. Similarly, plant 8 from family 3 was an effective pollen and egg parent with 12 of 17 unrelated plants with which it was crossed. Perhaps members of these families were homozygous for the same $S$-alleles. 
In three families $(6,16$ and 29), plants successfully crossed with most of their sibs as both pollen and egg parents. The results of the family 6 diallel is illustrated in Table 5. No functional incompatibility system would yield such a high percentage of successful crossing combinations in a family derived by selfing a single plant.

The genotypes assigned to the 24 parental plants whose self-families contained both homozygotes are presented in Table 6 . The total number of $S$-alleles examined in this experiment was $2 \times 24=48$, of which 30 turned out to be different. Seventeen alleles occurred once, eight alleles occurred twice, and five alleles occurred three times.

The equality of $S$-allele frequency was tested by the following statistic:

$\chi^{2}=(n-1)\left(C_{2 \mathrm{j}}-4 r^{2} / n\right) /(2 r-4 r / n)$,

where $C_{\mathrm{j}}$ is the number of times an allele occurs, $n$ is the number of alleles, and $r$ is the number of plants tested (Mantel, 1974; Appendix, Campbell \& Lawrence, 1981b). The observed inequality in allele frequencies is not statistically significant $\left(\chi^{2}=11.13\right.$, $P>0.05)$. Indeed, the fit of the data to the hypothesis of equal allele frequencies is surprisingly high, $P=0.998$.

\section{Discussion}

Diallels within self-sibships indicate that Phlox drummondii possesses a gametophytic system of selfincompatibility which is controlled by a single gene with multiple alleles. In most species with gametophytic self-incompatibility, pollen tube growth is arrested in the style or ovary (Richards, 1986). However, in this species (Levin, 1975, 1985), and some others (e.g. Oenothera organensis, Emerson, 1940; Papaver rhoeas, Lawrence, 1975), self-pollen inhibition is stigmatic. All

Table 5 Percentage fruit-set in a diallel in family 6

\begin{tabular}{|c|c|c|c|c|c|c|c|c|c|}
\hline \multirow{2}{*}{$\begin{array}{l}\text { Egg } \\
\text { parent }\end{array}$} & \multicolumn{9}{|c|}{ Pollen parent } \\
\hline & 1 & 2 & 3 & 4 & 5 & 6 & 7 & 8 & 9 \\
\hline 1 & & 50 & 25 & 50 & 75 & 0 & 75 & 100 & 100 \\
\hline 2 & 75 & & 0 & 75 & 0 & 75 & 75 & 0 & 100 \\
\hline 3 & 25 & 50 & & 50 & 0 & 75 & 100 & 50 & 50 \\
\hline 4 & 50 & 0 & 0 & & 75 & 50 & 100 & 100 & 0 \\
\hline 5 & 25 & 25 & 75 & 0 & & 75 & 75 & 100 & 100 \\
\hline 6 & 50 & 75 & 50 & 0 & 75 & & 0 & 75 & 75 \\
\hline 7 & 75 & 0 & 75 & 25 & 0 & 75 & & 50 & 100 \\
\hline 8 & 0 & 50 & 75 & 0 & 75 & 100 & 0 & & 50 \\
\hline 9 & 75 & 75 & 0 & 75 & 75 & 50 & 75 & 0 & \\
\hline
\end{tabular}

of the aforementioned species have binucleate pollen, which is typical of species with gametophytic selfincompatibility.

Thirty $S$-alleles were detected in the Lytle Phlox population. This number is similar to that found in populations of other species with gametophytic selfincompatibility, and is consistent with the expectation of great allele diversity. In one of two Papaver rhoeas populations in which 36 plants were tested, $30 \mathrm{~S}$ alleles were found; in the other $26 S$-alleles were found (Lawrence \& O'Donnell, 1981). Thirty-one $S$-alleles were found in a sample of 51 plants from a third population. Thirty-seven plants of Oenothera organensis contained $28 S$-alleles (Emerson, 1939). Twenty-five plant samples of two Trifolium repens populations yielded 36 and $39 S$-alleles, respectively (Atwood, 1944). Williams \& Williams (1947) found $41 S$-alleles in 24 Trifolium pratense plants from one population and 35 alleles in 19 plants from a second population.

The sample sizes used in the aforementioned studies are likely to be too small to contain the total number of $S$-alleles in a large population. This number can be estimated by iteration of

$n=N\left[1-(1-2 / N)^{\mathrm{r}}\right]$

when $n$ is the number of alleles observed, $r$ is the number of plants tested and $N$ is the estimate of the number of alleles in the population (Paxman, 1963).

The estimated number of alleles in the Phlox population is $N=45$. This number does not seem unrealistic given that the Lytle population contains several thousands of plants and has been in existence for at least five decades. Wright (1939) has shown that approximately 5000 individuals is the minimum population size required to maintain $45 S$-alleles given a mutation rate of $1 \times 10^{-6}$ and that the population is in equilibrium (Wright, 1939).

Table $6 S$-genotype of 24 Lytle plants

\begin{tabular}{cccc}
\hline Plant & Genotype & Plant & Genotype \\
\hline 1 & 1,2 & 13 & 12,21 \\
2 & 3,4 & 14 & 17,22 \\
3 & 5,6 & 15 & 19,23 \\
4 & 7,8 & 16 & 24,25 \\
5 & 9,10 & 17 & 26,27 \\
6 & 2,11 & 18 & 2,28 \\
7 & 12,13 & 19 & 1,16 \\
8 & 14,15 & 20 & 19,28 \\
9 & 16,17 & 21 & 9,26 \\
10 & 1,18 & 22 & 6,29 \\
11 & 5,7 & 23 & 6,30 \\
12 & 19,20 & 24 & 4,16 \\
\hline
\end{tabular}


$S$-alleles are expected to have approximately the same frequencies, given that the population is in equilibrium and that the $S$-locus is unaffected by selection on other loci and has no pleiotropic effect (Wright, 1939). The approximate equality of $S$-alleles was evident in the Lytle Phlox population and in Emerson's (1939) Oenothera organensis population. It was not the case in three Papaver rhoeas populations (Lawrence \& O'Donnell, 1981). The basis for the inequality remains to be determined.

Cross-compatibility within Phlox families may be controlled by factors which modify $S$-gene action. This is evident in the diallels of three families, in which most crossing combinations were successful. Ostensibly pollen grains which share an $S$-allele with the pistil are nevertheless functional. This phenomenon is referred to as pseudo-compatibility; and it has been demonstrated in numerous species (Ascher, 1976; de Nettancourt, 1977). The possibility that the anomalous crossing behaviour in these families is from segregating self-fertility $\left(S_{f}\right)$ alleles is remote, because the parental plants were self-incompatible.

Pseudo-compatibility has been demonstrated in several wild populations and several cultivars of Phlox drummondii (Levin, 1975, 1985). In wild plants it is usually manifested as low seed-set on self-pollination (less than 20 per cent), and as delayed and poor stigmatic germination of self pollen. However, some plants, especially cultivars, are highly self-compatible and self-fertile. Nevertheless, mixtures of self and cross pollen on stigmas of such plants yield mostly cross progeny (Levin, 1975).

Pseudo-compatibility jeopardizes the utility of any breeding scheme designed to identity $S$-genotypes. Crosses that would be unsuccessful in fully self-incompatible plants may be variously successful, and yield inconsistent and incomprehensible crossing patterns. This means that weakly self-compatible species are poor candidates for studying $S$-gene polymorphism.

\section{Acknowledgements}

This study was supported by National Science Foundation grant BSR-8614142. I am indebted to Ellen Brack for her assistance in the breeding programme, and to an anonymous reviewer for valuable comments.

\section{References}

ASCHER, P. 1976. Self-incompatibility systems in floricultural crops. Acta Hort., 63, 205-215.

ATwooD, s. s. 1944. Oppositional alleles in natural populations of Trifolium repens. Genetics, 29, 428-435.
BATEMAN, A. J. 1954. Self-incompatibility systems in angiosperms. II. Iberis amara. Heredity, 8, 305-332.

CAMPBELL, J. M. AND LAWRENCE M. D. 1981a. The population genetics of the self-incompatibility polymorphism in Papaver rhoeas. I. The number and distribution of $S$ alleles in families from three localities. Heredity, 46, 69-79.

CAMPBELL, J. M. AND LAWRENCE, M. D. 1981b. The population genetics of the self-incompatibilty polymorphism in Papaver rhoeas. II. The number and frequency of $S$-alleles in a natural population (R106). Heredity, 46, 81-90.

CROSBY, J. L. 1966. Self-incompatibility alleles in the population of Oenothera organensis. Evolution, 20, 567-579.

EMERSON, s. 1939. A preliminary survey of the Oenothera organensis population. Genetics, 24, 524-537.

EMERSON, S. 1940. Growth of incompatible tubes in Oenothera organensis. Bot. Gaz., 191, 890-911.

EWENS, w. J. 1964. On the problem of self-sterility alleles. Heredity, 21, 1433-1438.

FISHER, R. A. 1958. The Genetical Theory of Natural Selection, 2nd rev. ed. Dover Publications, New York.

FORD, M. A. AND KAY, Q. O. N. 1985. The genetics of incompatibility in Sinapis arvensis L. Heredity, 54, 99-102.

KARRON, J. D., MARSHALL, D. L. AND OLIVERAS, D. M. 1990. Number of sporophytic self-incompatibility alleles in populations of wild radish. Theor. Appl. Genet, 79, 457-460.

LAWRENCE, M. J. 1975. The genetics of self-incompatibility in Papaver rhoeas. Proc. R. Soc. Lond B, 188, 275-285.

LAWRENCE, M. J. AND O'DONNELL, S. 1981. The population genetics of the self-incompatibility polymorphism in Papaver rhoeas. II. The number and frequency of $S$-alleles in two further natural populations (R 102 and R 104). Heredity, 47, 53-61.

LEVIN, D. A. 1975. Gametophytic selection in Phlox. In: D. L. Mulcahy (ed.) Gamete Competition in Plants and Animals, American Elsevier, New York, pp. 207-217.

LEVIN, D. A. 1985. Reproductive character displacement in Phlox. Evolution, 39, 1275-1281.

LEVIN, D. A. 1989. Proximity-dependent cross-compatibility in Phlox. Evolution, 43, 1114-1116.

MANTEL, N. 1974. Approaches to a health research occupancy problem. Biometrics, 30, 355-362.

NAGYLAKI, T. 1975. The deterministic behaviour of selfincompatibility alleles. Genetics, 79, 545-550.

NETTANCOURT, D. DE. 1977. Incompatibility in Angiosperms. Springer-Verlag, Berlin.

PAXMAN, G. J. 1963. The maximum likelihood estimation of the number of self-sterility alleles in a population. Genetics, 48, 1029-1032.

Richards, A. J. 1986. Plant Breeding Systems. Allen \& Unwin, London.

SAMPSON, D. R. 1967. Frequency and distribution of selfincompatibility alleles in Raphanus raphanistrum. Genetics, 56, 241-251.

STEVENS, J. P. AND KAY, Q. O. N. 1989. The number of loci controlling the sporophytic self-incompatibility system in Sinapis arvensis L. Heredity, 61, 411-418.

WATKINS, L. AND LEVIN, D. A. 1990. Outcrossing rates as related 
to plant density in Phlox drummondii. Heredity, 65, 81-89.

WILLIAMS, R. D. AND wiLliams, w. 1947. Genetics of red clover (Trifolium pratense L.) compatibility. III. The frequency of incompatibility $S$-alleles in two non-pedigree populations of red clover. J. Genet., 48, 67-79.

WRIGHT, s. 1939. The distribution of self-sterility alleles in populations. Genetics, 24, 538-552.
WRIGHT, s. 1964. The distribution of self-incompatibility alleles in populations. Evolution, 18, 609-619.

YOKOYAMA, S. AND NEI, M. 1979. Population dynamics of sex determining alleles in honeybees and self-incompatibility alleles in plants. Genetics, 91, 609-626.

YOKOYAMA, S. AND HETHERINGTON, L. E. 1982. The expected number of self-incompatibility alleles in finite plant populations. Heredity, 48, 299-303. 